Braz J Med Biol Res, September 2011, Volume 44(9) 883-889

doi: 10.1590/S0100-879X2011007500094

Central chemoreceptors and neural mechanisms of cardiorespiratory control

T.S. Moreira, A.C. Takakura, R.S. Damasceno, B. Falquetto, L.T. Totola, C.R. Sobrinho, D.T. Ragioto and F.P. Zolezi

The Brazilian Journal of Medical and Biological Research is partially financed by

\section{足CNPq}

da Ciência e Tecnolorio

Institutional Sponsors
DFAPESP
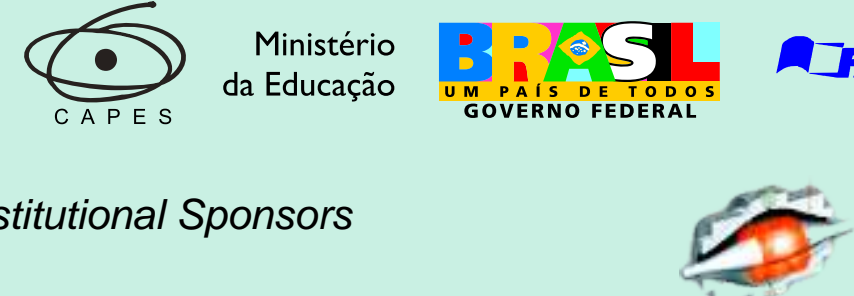

singo
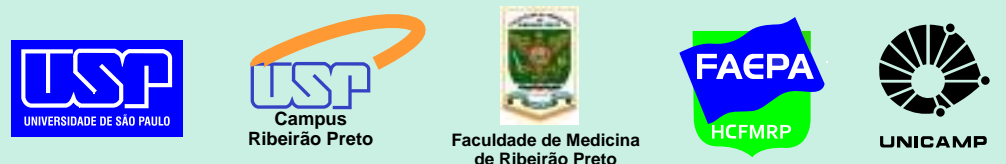

ФSHIMADZU

Explore High - Performance MS In Prbitrap Technology

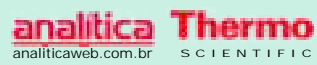




\title{
Central chemoreceptors and neural mechanisms of cardiorespiratory control
}

\author{
T.S. Moreira ${ }^{1}$, A.C. Takakura², R.S. Damasceno1 ${ }^{1}$, B. Falquetto ${ }^{1}$, \\ L.T. Totola ${ }^{1}$, C.R. Sobrinho ${ }^{1}$, D.T. Ragioto ${ }^{1}$ and F.P. Zolezi ${ }^{1}$ \\ ${ }^{1}$ Departamento de Fisiologia e Biofísica, ${ }^{2}$ Departamento de Farmacologia, \\ Instituto de Ciências Biomédicas, Universidade de São Paulo, São Paulo, SP, Brasil
}

\begin{abstract}
The arterial partial pressure $\left(\mathrm{P}_{\mathrm{CO}_{2}}\right)$ of carbon dioxide is virtually constant because of the close match between the metabolic production of this gas and its excretion via breathing. Blood gas homeostasis does not rely solely on changes in lung ventilation, but also to a considerable extent on circulatory adjustments that regulate the transport of $\mathrm{CO}_{2}$ from its sites of production to the lungs. The neural mechanisms that coordinate circulatory and ventilatory changes to achieve blood gas homeostasis are the subject of this review. Emphasis will be placed on the control of sympathetic outflow by central chemoreceptors. High levels of $\mathrm{CO}_{2}$ exert an excitatory effect on sympathetic outflow that is mediated by specialized chemoreceptors such as the neurons located in the retrotrapezoid region. In addition, high $\mathrm{CO}_{2}$ causes an aversive awareness in conscious animals, activating wakepromoting pathways such as the noradrenergic neurons. These neuronal groups, which may also be directly activated by brain acidification, have projections that contribute to the $\mathrm{CO}_{2}$-induced rise in breathing and sympathetic outflow. However, since the level of activity of the retrotrapezoid nucleus is regulated by converging inputs from wake-promoting systems, behavior-specific inputs from higher centers and by chemical drive, the main focus of the present manuscript is to review the contribution of central chemoreceptors to the control of autonomic and respiratory mechanisms.
\end{abstract}

Key words: Chemoreflex; Cardiorespiratory responses; Ventrolateral medulla; Sympathetic nerve activity; Phrenic nerve activity

\section{Introduction}

Cardiorespiratory integration occurs at multiple levels in the central nervous system (CNS) to coordinate breathing and sympathetic outflow. One key example is that an increase in CNS arterial partial pressure of carbon dioxide $\left(\mathrm{PCO}_{2}\right)$ (henceforth called central chemoreceptor stimulation) increases breathing and sympathetic nerve activity (SNA) $(1,2)$.

Several lines of evidence suggest that brain $\mathrm{PCO}_{2}$ is detected via changes in extracellular fluid $\mathrm{pH}$, but the molecular and network basis of central chemoreceptors is still poorly understood (3). Recently, new data suggested that adenosine-triphosphate (ATP) could be released in response to changes in $\mathrm{PCO}_{2}$ rather than extracellular $\mathrm{pH}$ and occurs via gap junction hemichannel connexin 36 (4).

The initial concept of specialized chemoreceptors originates from manipulations of the ventral medullary surface (acidification or lesions) performed since the early 1960s (5). More recently, focal acidification of several other brain- stem regions in vivo (nucleus of the solitary tract (NTS), retrotrapezoid nucleus (RTN), raphe, pre-Bötzinger complex, locus coeruleus (LC), hypothalamus) has also been found to activate breathing and sympathetic outflow and this evidence has led to the view that central chemoreceptor stimulation is a "distributed" property (3).

However, one important question that remains is: how widely distributed is the central chemoreceptor property? Does each of the regions responsive to acidification contain central chemoreceptors involved in cardiorespiratory control?

In this short review, we consider a modern view about the brain areas involved in cardiorespiratory control elicited by central chemoreceptor stimulation.

\section{Role of the brainstem in cardiorespiratory control}

Anatomically, the central interaction between the respi-

Correspondence: T.S. Moreira, Departamento de Fisiologia e Biofísica, Instituto de Ciências Biomédicas, USP, Av. Prof. Lineu Prestes, 1524, 05508-900 São Paulo, SP, Brasil. Fax: +55-11-3091-7285. E-mail: tmoreira@icb.usp.br

Presented at the XV Simpósio Brasileiro de Fisiologia Cardiovascular, São Paulo, SP, Brazil, February 2-5, 2011.

Received February 10, 2011. Accepted July 15, 2011. Available online July 29, 2011. Published September 16, 2011. 
ratory and cardiovascular systems has been extensively discussed in the literature (6-9). The respiratory control network consists of a long column of cells in the lateral brainstem that extends from the caudal medulla, along the ventrolateral medulla, to the dorsolateral pons, as well as to the NTS. A similar, if not overlapping, distribution of neurons has been identified for the cardiovascular control system $(10,11)$. On the basis of functional and anatomical criteria, cardiovascular physiologists have divided the ventrolateral medulla into three rostrocaudal regions, whereas respiratory physiologists have divided the same area into four regions (Figure 1). This anatomical evidence suggests that the cardiovascular and respiratory systems have some kind of interactions at the brainstem level.

\section{Rostral ventrolateral medulla presympathetic neurons as the main relay of the central sympathetic chemoreflex}

Normoxic hypercapnia raises blood pressure and activates SNA even after surgical removal of peripheral chemoreceptors and baroreceptors indicating that central chemoreceptors must be responsible for the effects of $\mathrm{CO}_{2}$ $(12,13)$. In anesthetized vagotomized and barodenervated cats, $\mathrm{CO}_{2}$ predominantly activates the phasic component of SNA, which happens to be synchronized with inspira-

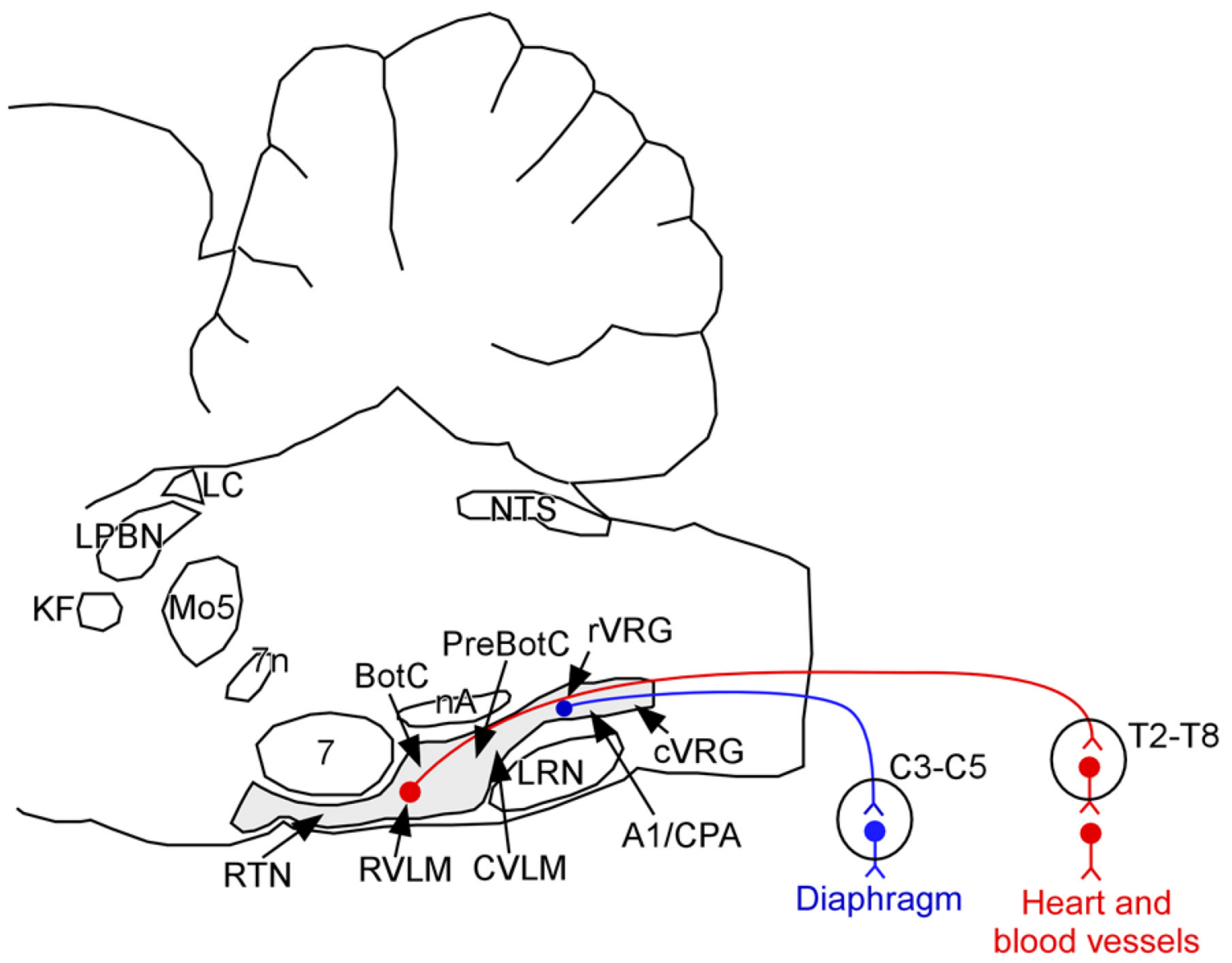

Figure 1. Main cardiorespiratory regions of the pons and medulla. The pontomedullary neurons that regulate the heart and vasomotor sympathetic outflow occur in a connected structure that extends from the spinomedullary junction to the dorsolateral pons. This parasagittal section from a rat lies about 1.8-1.9 mm lateral to the midline. The motor outflow to diaphragm and intercostal and airway respiratory muscles is generated within the same brain regions. The pre-Bötzinger region (PreBotC) contains neurons that are essential to inspiratory rhythm generation. $A 1 / C P A=$ region containing the $A 1$ group of noradrenergic neurons also called caudal pressor area; $\mathrm{BotC}=\mathrm{Bötzinger} \mathrm{region;} \mathrm{CVLM}=$ caudal ventrolateral medulla; $c$ VRG = caudal ventral respiratory group; C3-C5 = cervical spinal cord; KF = Kölliker-Fuse nucleus; LC = locus coeruleus; $L P B N=$ lateral parabrachial nucleus; LRN = lateral reticular nucleus; Mo5 = mesencephalic nucleus; nA = nucleus ambiguus; NTS = nucleus tractus solitarii; RVLM = rostral ventrolateral medulla; RTN = retrotrapezoid nucleus; rVRG = rostral ventral respiratory group; T2-T8 = thoracic spinal cord; 7 = facial motor nucleus; $7 \mathrm{n}=$ seventh nerve. 
tion (12). These data suggest that central chemoreceptors activate SNA via neurons that are either part of the central pattern generator (CPG) or are entrained by it (Figure 2). The existence of CPG-independent inputs from central chemoreceptors to the autonomic efferents is poorly documented, but must be considered since in the awake state, SNA seems to be increased by hypercapnia more evenly through the respiratory cycle (13). However, the most plausible mechanism is that $\mathrm{CO}_{2}$ activates central chemoreceptors that activate the CPG, which in turn activates the neurons that generate the sympathetic outflow.

In agreement with the hypothesis described above, the activity of the SNA doubled at steady state when end-expiratory $\mathrm{CO}_{2}$ rose from 5 to $10 \%(6,13)$. Central chemoreceptor stimulation with $10 \%$ end-expiratory $\mathrm{CO}_{2}$ also increases by $70 \%$ the activity of the rostral ventrolateral medulla (RVLM) presympathetic neurons $(14,15)$. Furthermore, the activation of RVLM neurons is patterned by the central respiratory cycle in the same manner as the SNA (14-16). The central respiratory pattern generator is important for the synchronization of the activity of presympathetic RVLM neurons with respiratory activity, but not for the overall increase of activity of these neurons during CNS acidification $(14,17,18)$

lonotropic glutamatergic receptor blockade in the RVLM eliminates SNA activation by peripheral chemoreceptors $(14,17)$, whereas it does not attenuate the central sympathetic chemoreflex. The effect of NMDA or non-NMDA

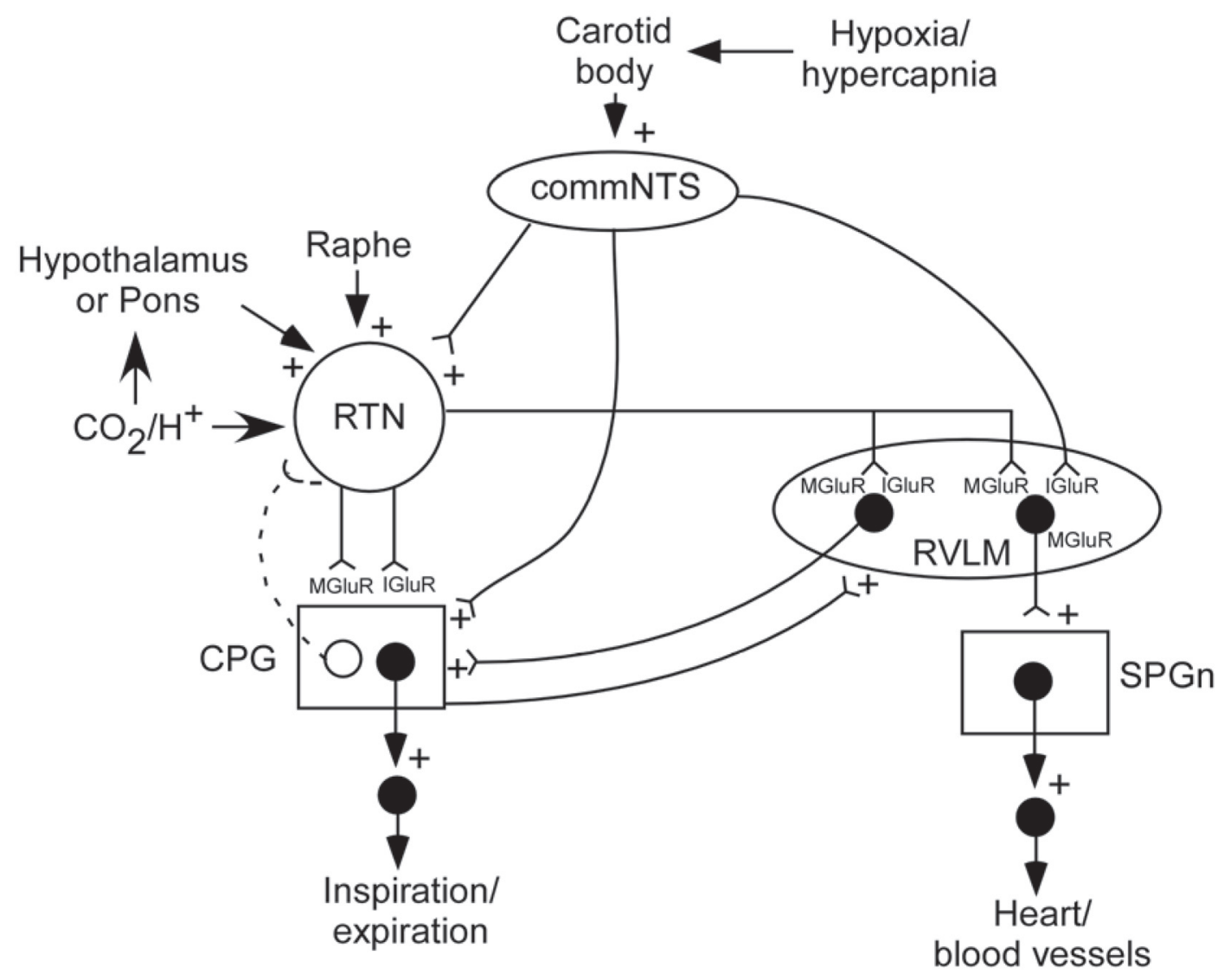

Figure 2. Scheme showing the contribution of the RTN to the central sympathetic chemoreflex. Signals from central or peripheral chemoreceptors may directly or indirectly affect the activity of several medullary areas, including the RTN, NTS, RVLM, and CPG, which affect sympathetic discharge to heart and blood vessels and to respiratory muscles. An essential step for motor neuron hypercapnia-induced phrenic nerve activity is activation of RTN neurons by $\mathrm{CO}_{2} / \mathrm{H}^{+}$, which in turn send excitatory signals to activate the $\mathrm{CPG}$, either directly or through activation of metabotropic and ionotropic glutamate receptors in the RVLM. Signals from the RTN that activate metabotropic receptors in the RVLM may also increase sympathetic activity to the cardiovascular system (24). CPG = central pattern generator; commNTS = commissural nucleus tractus solitarii; IgluR = glutamatergic ionotropic receptors; MgluR = glutamatergic metabotropic receptors; RTN = retrotrapezoid nucleus; RVLM = rostral ventrolateral medulla; $\mathrm{SPG}=$ sympathetic preganglionic neurons. 
receptor blockade inside the RVLM on the peripheral chemoreflex is consistent with independent anatomical and electrophysiological evidence that the signals from peripheral chemoreceptor activation reach RVLM and RTN neurons by a direct glutamatergic projection from the commissural NTS (commNTS) (19-22). The central sympathetic chemoreflex was reduced by metabotropic receptor blockade, but not by ionotropic glutamatergic antagonists inside the RVLM, which suggests that central and peripheral chemoreflexes do not share the same mechanisms to produce sympathetic activation (Figure 2).

Because the RVLM presympathetic neurons do not seem to be intrinsically $\mathrm{pH}$-sensitive (23), their response to $\mathrm{CO}_{2}$ must rely on synaptic inputs, especially from RTN neurons that are a plausible source of $\mathrm{CO}_{2}$-dependent excitation (24).

\section{The retrotrapezoid nucleus contributes to the sympathoexcitation caused by hypercapnia}

The tonic activation of SNA caused by hypercapnia in the absence of central respiratory drive suggests that $\mathrm{CO}_{2}$ may be detected by CNS neurons that are not part of the respiratory rhythm generator or by neurons that are normally respiratory modulated, but respond to $\mathrm{CO}_{2}$ in a tonic fashion when the respiratory network is silenced. The RTN chemoreceptor neurons fit these requirements both in vivo and in vitro (25-28).

Recently, we have shown that inhibition of the chemosensitive neurons located in the RTN eliminated resting breathing and reduced the sympathoexcitatory responses produced by central chemoreceptor activation (24). The results suggest that central chemoreceptor-induced phrenic nerve activity (PNA) is dependent on RTN, as previously demonstrated $(22,24,27)$, whereas sympathoexcitation and pressor responses are only partially mediated by RTN (24). The reduced sympathoexcitation produced by hypercapnia after injection of the NMDA glutamate antagonist (AP-5) into the RTN, might also be the result of the decrease in the excitability of RVLM presympathetic neurons after removing baseline facilitatory glutamatergic signals from the RTN (Figure 2).

RTN cells are heterogeneous with regard to respiratory modulation but cases of respiratory patterns that are identical to those of RVLM presympathetic neurons (early inspiratory or post-inspiratory peak) have been found, consistent with the possibility that these particular RTN neurons drive excitatory inputs to RVLM presympathetic neurons $(29,30)$. In addition, the RTN neurons are glutamatergic and innervate the RVLM region (25-27,31,32).

The literature has recently discussed the involvement of astrocytes in the control of $\mathrm{pH}$-sensitive neurons (33). There is increasing evidence that ATP, possibly released by astrocytes, is an important mediator of central chemoreception (34). In vivo studies have shown that hypercapnia caused a discrete release of ATP within the RTN (33), which might influence RTN neurons that signal to increase SNA through metabotropic receptors within the RVLM $(24,33)$.

\section{Role of the pontine catecholaminergic system in central sympathetic chemoreflex}

Noradrenergic neurons are classified as a wake-promoting system that innervates the brainstem autonomic network $(35,36)$. These neurons contribute to the mechanism that maintains breathing and sympathetic outflow during waking regardless of the $\mathrm{CO}_{2}$ level (32). This mechanism could be activated when brain $\mathrm{CO}_{2}$ reaches levels that cause arousal, because severe hypercapnia is an especially aversive stimulus in mammals $(37,38)$. Based on this information, the contribution of the pontine catecholaminergic system to the sympathetic component of the central chemoreflex is plausible a priori.

The noradrenergic neurons located in the dorsolateral pons (A6 - LC) and in the ventrolateral pons (A5) are modestly activated by hypercapnia (39-42). The A6 neurons are innervated by RVLM/C1 neurons, which are $\mathrm{CO}_{2}$ responsive in vivo (14) and have a very wide brain projection, suggesting that the LC is finely tuned to regulate arousal (43).

The ventrolateral pontine A5 noradrenergic neurons have intrinsic properties that are very similar to those of the LC. A5 noradrenergic neurons have spinal projections that target the intermediolateral cell column and the central circuitry that generates the sympathetic outflow $(44,45)$. In addition, these cells are activated by nociceptive stimuli, inhibited by the administration of alpha-2 adrenergic receptor agonists and activated by hypoxia and display central respiratory modulation (46-49). There is some evidence that adrenergic A5 neurons may act as chemosensors for $\mathrm{CO}_{2}$, since the activity of these cells is significantly increased by inspired $\mathrm{CO}_{2}$ (42). In addition, stimulation of the $\mathrm{A} 5$ region with glutamate in conscious rabbits evokes a dose-dependent excitatory response in the renal SNA (50). Thus, based on the information described above, we could speculate that A5 noradrenergic neurons contribute to the activation of the sympathetic system and breathing by hypercapnia in rats. A5 noradrenergic neurons partially contribute to the increase in breathing and sympathetic outflow produced by raising end-expiratory $\mathrm{CO}_{2}$ in urethaneanesthetized animals (Taxini CL, Takakura AC, Gargaglioni $\mathrm{LH}$, Moreira TS, unpublished results) It is also reasonable to assume that these wake-promoting systems make a significant contribution to the cardiorespiratory stimulation associated with several breathing disorders such as obstructive sleep apnea.

\section{Exercise and central sympathetic chemoreflex}

The autonomic and respiratory mechanisms activated during exercise are still a mystery in physiology. Exercise 
increases breathing, cardiac output and blood pressure. The large increase in cardiac output during exercise minimizes the changes in blood $\mathrm{P}_{\mathrm{CO}_{2}}$ caused by the increased metabolic production of this gas. Two neural mechanisms have been proposed to be involved in these cardiorespiratory responses $(51,52)$. First, afferent information arising from contracting muscle (group III and IV afferents) activates cardiorespiratory areas in the CNS and causes important cardiorespiratory changes. This has often been termed "exercise pressor reflex". The second mechanism is known as "central command". The "central command" consists of forebrain mechanisms (hypothalamic areas) that promote activation of medullary areas involved in cardiorespiratory control (53-55).

The activation of muscle metaboreceptors (group III and IV afferents) is responsive to the metabolic products of exercise $\left(\mathrm{H}^{+}\right.$, lactate, $\left.\mathrm{K}^{+}\right)$, to muscle tension and to temperature. They may also respond to vessel distention, particularly at the muscle venule level and thus could be monitoring muscle blood flow by encoding the degree of recruitment of the muscular postcapillary network. These properties seem appropriate to encode the overall metabolic activity of muscles leading to the view that the summation of all locally determined perfusion rates by group III and IV afferents could serve as the signal needed to match ventilation and cardiac output to metabolic rate. The central pathways responsible for these effects are not known.

In decerebrate cats, locomotor activity occurs spontaneously or can be elicited by electrical or chemical stimulation of specific brain regions (i.e., hypothalamic or mesencephalic "locomotor" regions). An especially detailed study by Eldridge et al. (51) showed that this locomotor activity is always associated with hyperpnea and a rise in blood pressure. The cardiorespiratory stimulation could not have been due to chemoreceptor activation since locomotion/ exercise caused a mild hypocapnia. At most, the role of chemoreceptors might be to limit the extent of exerciseinduced hypocapnia. The concept of a central command is very much in line with recent theories concerning the genesis of autonomic response patterns by the CNS (56), but current knowledge of the specific central networks that

\section{References}

1. Somers VK, Mark AL, Zavala DC, Abboud FM. Contrasting effects of hypoxia and hypercapnia on ventilation and sympathetic activity in humans. J Appl Physiol 1989; 67: 2101-2106.

2. Duffin J. Modelling the respiratory chemoreflex control of acid-base balance. Conf Proc IEEE Eng Med Biol Soc 2005; 6: 5836-5839.

3. Huckstepp RT, Id Bihi R, Eason R, Spyer KM, Dicke N, Willecke $\mathrm{K}$, et al. Connexin hemichannel-mediated $\mathrm{CO}_{2}-$ dependent release of ATP in the medulla oblongata contributes to central respiratory chemosensitivity. J Physiol 2010; causes cardiorespiratory stimulation during exercise is still speculative.

The hypothalamic locomotor region may overlap or be able to recruit the dorsomedial hypothalamic nucleus and/or perifornical region, which is a source of excitatory projections to the medulla oblongata including the presympathetic neurons of the RVLM and the central chemoreceptor neurons of the RTN $(55,57)$. Anatomical and physiological evidence suggests that the activity of RTN neurons is regulated by descending inputs from the hypothalamus and this pathway is activated during mild exercise (Falquetto B, Takakura AC, Moreira TS, unpublished data). This important evidence suggests that the chemoreceptor neurons within the RTN region are not just $\mathrm{pH} / \mathrm{P}_{\mathrm{CO}_{2}}$ detectors, but could also be regulated by synaptic inputs.

\section{Conclusions}

The pontomedullary region contains a set of structures that are essential for the reflex stabilization of arterial pressure and to coordinate breathing with oxygen delivery to various tissues. Chemoreceptor stimulation probably recruits a hierarchy of pathways depending on the intensity of the stimulus and the presence or absence of anesthesia. Mild stimuli such as those that regulate $\mathrm{CO}_{2}$ homeostasis under normal circumstances probably utilize discrete connections between the chemoreceptors and specific components of the lower brainstem cardiorespiratory network. Strong stimuli such as those caused by airway blockade probably also recruit pathways involved in stress and arousal (catecholaminergic neurons). In addition, recent studies from our laboratory have suggested that the level of activity of RTN neurons is regulated by converging inputs from behaviorspecific inputs from higher centers involved in exercise.

\section{Acknowledgments}

Research supported by FAPESP (\#06/60174-9 to T.S. Moreira, \#10/09776-3 to A.C. Takakura, \#10/15692-7 to R.S. Damasceno, \#10/12590-0 to B. Falquetto, and \#10/15086-0 to D.T. Ragioto).
588: 3901-3920.

4. Nattie E, Li A. Central chemoreception 2005: a brief review. Auton Neurosci 2006; 126-127: 332-338.

5. Loeschcke $\mathrm{HH}$. Central chemosensitivity and the reaction theory. J Physiol 1982; 332: 1-24.

6. Guyenet PG, Stornetta RL, Abbott SB, Depuy SD, Fortuna $\mathrm{MG}$, Kanbar R. Central $\mathrm{CO}_{2}$ chemoreception and integrated neural mechanisms of cardiovascular and respiratory control. J Appl Physiol 2010; 108: 995-1002.

7. Stornetta RL. Neurochemistry of bulbospinal presympathetic neurons of the medulla oblongata. J Chem Neuroanat 2009; 
38: $222-230$

8. Zoccal DB, Machado BH. Sympathetic overactivity coupled with active expiration in rats submitted to chronic intermittent hypoxia. Respir Physiol Neurobiol 2010; 174: 98-101.

9. Zoccal DB, Machado BH. Coupling between respiratory and sympathetic activities as a novel mechanism underpinning neurogenic hypertension. Curr Hypertens Rep 2011; 13: 229-236.

10. Guyenet PG. The sympathetic control of blood pressure. Nat Rev Neurosci 2006; 7: 335-346.

11. Stornetta RL. Identification of neurotransmitters and colocalization of transmitters in brainstem respiratory neurons. Respir Physiol Neurobiol 2008; 164: 18-27.

12. Millhorn DE, Eldridge FL. Role of ventrolateral medulla in regulation of respiratory and cardiovascular systems. J Appl Physiol 1986; 61: 1249-1263.

13. Oikawa S, Hirakawa H, Kusakabe T, Nakashima Y, Hayashida Y. Autonomic cardiovascular responses to hypercapnia in conscious rats: the roles of the chemo- and baroreceptors. Auton Neurosci 2005; 117: 105-114.

14. Moreira TS, Takakura AC, Colombari E, Guyenet PG. Central chemoreceptors and sympathetic vasomotor outflow. $J$ Physiol 2006; 577: 369-386.

15. Haselton JR, Guyenet PG. Central respiratory modulation of medullary sympathoexcitatory neurons in rat. Am J Physiol 1989; 256: R739-R750.

16. McAllen RM. Central respiratory modulation of subretrofacial bulbospinal neurones in the cat. J Physiol 1987; 388: 533545.

17. Koshiya N, Huangfu D, Guyenet PG. Ventrolateral medulla and sympathetic chemoreflex in the rat. Brain Res 1993; 609: 174-184.

18. Mandel DA, Schreihofer AM. Modulation of the sympathetic response to acute hypoxia by the caudal ventrolateral medulla in rats. J Physiol 2009; 587: 461-475.

19. Sun MK, Reis DJ. NMDA receptor-mediated sympathetic chemoreflex excitation of RVL-spinal vasomotor neurones in rats. J Physiol 1995; 482 (Part 1): 53-68.

20. Aicher SA, Saravay RH, Cravo S, Jeske I, Morrison SF, Reis DJ, et al. Monosynaptic projections from the nucleus tractus solitarii to $\mathrm{C} 1$ adrenergic neurons in the rostral ventrolateral medulla: comparison with input from the caudal ventrolateral medulla. J Comp Neurol 1996; 373: 62-75.

21. Guyenet PG. Neural structures that mediate sympathoexcitation during hypoxia. Respir Physiol 2000; 121: 147-162.

22. Takakura AC, Moreira TS, Colombari E, West GH, Stornetta $\mathrm{RL}$, Guyenet PG. Peripheral chemoreceptor inputs to retrotrapezoid nucleus (RTN) $\mathrm{CO}_{2}$-sensitive neurons in rats. $J$ Physiol 2006; 572: 503-523.

23. Lazarenko RM, Milner TA, Depuy SD, Stornetta RL, West $\mathrm{GH}$, Kievits JA, et al. Acid sensitivity and ultrastructure of the retrotrapezoid nucleus in Phox2b-EGFP transgenic mice. $J$ Comp Neurol 2009; 517: 69-86.

24. Takakura AC, Colombari E, Menani JV, Moreira TS. Ventrolateral medulla mechanisms involved in cardiorespiratory responses to central chemoreceptor activation in rats. $A m \mathrm{~J}$ Physiol Regul Integr Comp Physiol 2011; 300: R501-R510.

25. Mulkey DK, Stornetta RL, Weston MC, Simmons JR, Parker A, Bayliss DA, et al. Respiratory control by ventral surface chemoreceptor neurons in rats. Nat Neurosci 2004; 7: 13601369.

26. Stornetta RL, Moreira TS, Takakura AC, Kang BJ, Chang
DA, West GH, et al. Expression of Phox $2 b$ by brainstem neurons involved in chemosensory integration in the adult rat. J Neurosci 2006; 26: 10305-10314.

27. Takakura AC, Moreira TS, Stornetta RL, West GH, Gwilt JM, Guyenet PG. Selective lesion of retrotrapezoid Phox2bexpressing neurons raises the apnoeic threshold in rats. $J$ Physiol 2008; 586: 2975-2991.

28. Wenker IC, Kreneisz O, Nishiyama A, Mulkey DK. Astrocytes in the retrotrapezoid nucleus sense $\mathrm{H}^{+}$by inhibition of a Kir4.1-Kir5.1-like current and may contribute to chemoreception by a purinergic mechanism. J Neurophysiol 2010; 104 : 3042-3052.

29. Guyenet PG, Mulkey DK, Stornetta RL, Bayliss DA. Regulation of ventral surface chemoreceptors by the central respiratory pattern generator. J Neurosci 2005; 25: 8938-8947.

30. Molkov YI, Zoccal DB, Moraes DJ, Paton JF, Machado BH, Rybak IA. Intermittent hypoxia-induced sensitization of central chemoreceptors contributes to sympathetic nerve activity during late expiration in rats. J Neurophysiol 2011; 105: 3080-3091.

31. Rosin DL, Chang DA, Guyenet PG. Afferent and efferent connections of the rat retrotrapezoid nucleus. J Comp Neurol 2006; 499: 64-89.

32. Abbott SB, Stornetta RL, Fortuna MG, Depuy SD, West GH, Harris TE, et al. Photostimulation of retrotrapezoid nucleus phox $2 \mathrm{~b}$-expressing neurons in vivo produces long-lasting activation of breathing in rats. J Neurosci 2009; 29: 58065819.

33. Gourine AV, Kasymov V, Marina N, Tang F, Figueiredo MF, Lane S, et al. Astrocytes control breathing through $\mathrm{pH}$ dependent release of ATP. Science 2010; 329: 571-575.

34. Gourine AV, Llaudet E, Dale N, Spyer KM. ATP is a mediator of chemosensory transduction in the central nervous system. Nature 2005; 436: 108-111.

35. Aston-Jones G, Foote SL, Segal M. Impulse conduction properties of noradrenergic locus coeruleus axons projecting to monkey cerebrocortex. Neuroscience 1985; 15: 765777.

36. Aston-Jones G, Chen S, Zhu Y, Oshinsky ML. A neural circuit for circadian regulation of arousal. Nat Neurosci 2001; 4: 732-738.

37. Berthon-Jones M, Sullivan CE. Ventilation and arousal responses to hypercapnia in normal sleeping humans. J Appl Physiol 1984; 57: 59-67.

38. Moosavi SH, Golestanian E, Binks AP, Lansing RW, Brown R, Banzett RB. Hypoxic and hypercapnic drives to breathe generate equivalent levels of air hunger in humans. $J$ Appl Physiol 2003; 94: 141-154.

39. Elam M, Yao T, Thoren P, Svensson TH. Hypercapnia and hypoxia: chemoreceptor-mediated control of locus coeruleus neurons and splanchnic, sympathetic nerves. Brain Res 1981; 222: 373-381.

40. Haxhiu MA, Erokwu BO, Cherniack NS. The brainstem network involved in coordination of inspiratory activity and cholinergic outflow to the airways. J Auton Nerv Syst 1996; 61: 155-161.

41. Gourine AV, Llaudet E, Dale N, Spyer KM. ATP is a mediator of chemosensory transduction in the central nervous system. Nature 2005; 436: 108-111.

42. Biancardi V, Bicego KC, Almeida MC, Gargaglioni LH. Locus coeruleus noradrenergic neurons and $\mathrm{CO}_{2}$ drive to breathing. Pflugers Arch 2008; 455: 1119-1128. 
43. Kanbar R, Stornetta RL, Cash DR, Lewis SJ, Guyenet PG. Photostimulation of Phox $2 \mathrm{~b}$ medullary neurons activates cardiorespiratory function in conscious rats. Am J Respir Crit Care Med 2010; 182: 1184-1194.

44. Carter ME, Yizhar O, Chikahisa S, Nguyen H, Adamantidis A, Nishino $S$, et al. Tuning arousal with optogenetic modulation of locus coeruleus neurons. Nat Neurosci 2010; 13: 15261533.

45. Byrum CE, Guyenet PG. Afferent and efferent connections of the A5 noradrenergic cell group in the rat. J Comp Neurol 1987; 261: 529-542.

46. Andrade R, Aghajanian GK. Single cell activity in the noradrenergic A-5 region: responses to drugs and peripheral manipulations of blood pressure. Brain Res 1982; 242: 125135.

47. Byrum CE, Stornetta R, Guyenet PG. Electrophysiological properties of spinally-projecting A5 noradrenergic neurons. Brain Res 1984; 303: 15-29.

48. Huangfu DH, Koshiya N, Guyenet PG. A5 noradrenergic unit activity and sympathetic nerve discharge in rats. $A m \mathrm{~J}$ Physiol 1991; 261: R393-R402.

49. Guyenet PG, Koshiya N, Huangfu D, Verberne AJ, Riley TA. Central respiratory control of $A 5$ and $A 6$ pontine noradrenergic neurons. Am J Physiol 1993; 264: R1035-R1044.

50. Maiorov DN, Wilton ER, Badoer E, Petrie D, Head GA, Malpas SC. Sympathetic response to stimulation of the pontine A5 region in conscious rabbits. Brain Res 1999; 815: 227-236.

51. Eldridge FL, Millhorn DE, Kiley JP, Waldrop TG. Stimulation by central command of locomotion, respiration and circulation during exercise. Respir Physiol 1985; 59: 313-337.

52. Waldrop TG, Iwamoto GA. Point: supraspinal locomotor centers do contribute significantly to the hyperpnea of dynamic exercise. J Appl Physiol 2006; 100: 1077-1079.

53. Iwamoto GA, Wappel SM, Fox GM, Buetow KA, Waldrop TG. Identification of diencephalic and brainstem cardiorespiratory areas activated during exercise. Brain Res 1996; 726 : 109-122.

54. Padley JR, Kumar NN, Li Q, Nguyen TB, Pilowsky PM, Goodchild AK. Central command regulation of circulatory function mediated by descending pontine cholinergic inputs to sympathoexcitatory rostral ventrolateral medulla neurons. Circ Res 2007; 100: 284-291.

55. Fortuna MG, Stornetta RL, West GH, Guyenet PG. Activation of the retrotrapezoid nucleus by posterior hypothalamic stimulation. J Physiol 2009; 587: 5121-5138.

56. Saper CB. The central autonomic nervous system: conscious visceral perception and autonomic pattern generation. Annu Rev Neurosci 2002; 25: 433-469.

57. DiMicco JA, Samuels BC, Zaretskaia MV, Zaretsky DV. The dorsomedial hypothalamus and the response to stress: part renaissance, part revolution. Pharmacol Biochem Behav 2002; 71: 469-480. 